\title{
HIGHLY DISCRETE MAPPING OF THE GROWING SEASON TIME FRAMES AND TIME DYNAMICS
}

\author{
I. Rykin ${ }^{1}$, A. Shagnieva ${ }^{1}$, E. Panidi ${ }^{1, *}$, V. Tsepelev ${ }^{2}$ \\ ${ }^{1}$ Saint Petersburg State University, St. Petersburg, Russia - panidi@ya.ru, e.panidi@spbu.ru \\ ${ }^{2}$ Russian State Hydrometeorological University, St. Petersburg, Russia
}

KEY WORDS: Growing Seasons, GIS-based Mapping, Vegetation Indexes, NDWI, Google Earth Engine

\begin{abstract}
:
Growing season time frames can be estimated and mapped using the vegetation indexes mapping and analysis. This approach brings significant benefit consisted in the ability of detailed (highly discrete in the meaning of spatial resolution) mapping of spatial differences in growing season stage and length. In comparison with interpolation of ground air temperature (applied when using temperature to detect growing seasons), real spatial resolution raises to kilometers per pixel and higher, while nodes of ground observation network can be spaced by thousands of kilometers in some regions. Our ongoing study is devoted to design a processing chain for mapping of growing season time frames basing on vegetation indexes data with close-to-one-day time resolution. We used MOD09GA dataset as an initial data. Data processing was implemented in Google Earth Engine big geospatial data platform.
\end{abstract}

\section{INTRODUCTION}

Length, beginning and ending dates as well as some other parameters of growing season can be recognized also as secondary or indirect parameters of weather and climate, as the growing conditions of the plants are formed by such (primary) parameters as temperature, humidity, insolation, etc. Growing season is a period when the plants are able to vegetate.

Growing season time frames can be estimated and mapped basing on the analysis of surface air temperature dynamics and detection of the temperature crossing through some marker values that frame the period (growing season itself) with the temperature applicable for the phytomass growth. In addition to the full growing season detected this way, the summer growing season can be separated, when the temperature allows active development of vegetation cover (Tsepelev et al., 2015).

A number of studies shown that time frames of full growing season can be estimated by analysis of vegetation indexes data (Normalized Difference Vegetation Index - NDVI, Normalized Difference Water Index - NDWI, etc.) that can be derived from optical remote sensing materials (Delbart, et al., 2005; Medvedeva et al., 2008; Sekhon et al., 2010; Miklashevich, Bartalev, 2016). Our study show that NDWI can be applied also to detect spring, summer and autumn subseasons (Panidi, Tsepelev, 2017).

These estimations in their turn can be applied to monitor vegetation cover dynamics and change, and to estimate indirectly weather impact and climate change. Consequently, it is possible to ensure monitoring and estimation of regional weather and climate change hazards, and to elaborate a basis for risk areas detection and hazard prevention activities planning. Significant demand to the initial data in this case is the possibility to ensure enough spatial and time resolution of monitoring.

\section{DATA AND TOOLS}

In our study we use Gao's NDWI formula (Gao, 1996):

$$
N D W I=\frac{\rho_{0.86}-\rho_{1.24}}{\rho_{0.86}+\rho_{1.24}}
$$

where

$\rho_{0.86}=$ near-infrared reflectance

$\rho_{1.24}=$ short wave infrared reflectance

The Republic of Komi is selected as a study area, which is located in the north of European part of Russia (Fig. 1). This territory is located in a number of natural zones (taiga in the south and tundra in the north) and has differentiated relief surface and hydrological regime.

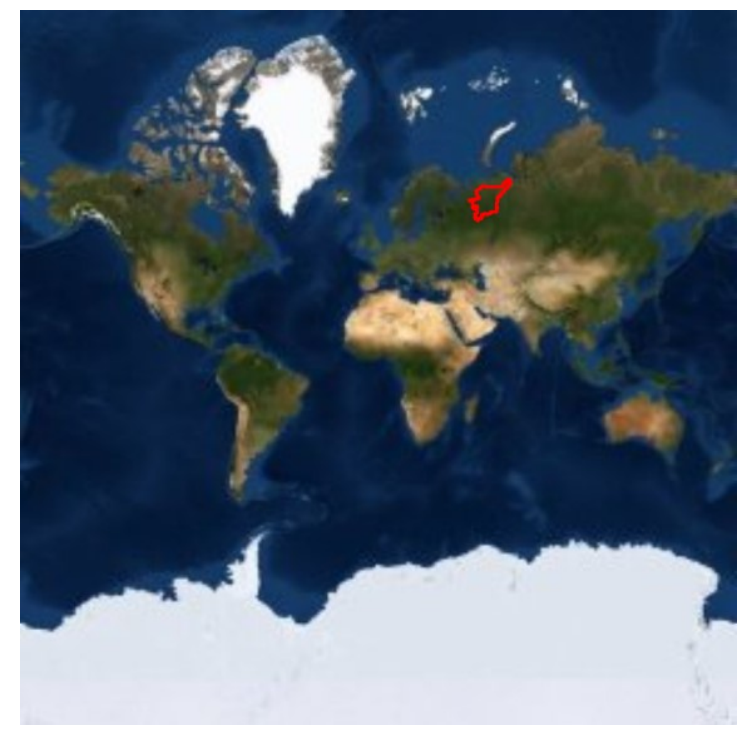

Figure 1. Location of the study area; Republic of Komi is marked by red contour; satellite imagery courtesy of the ESRI ArcGIS Online

\footnotetext{
* Corresponding author
} 
At the previous stages of the study, we conducted experiments with the MOD09A1 Version 6 product derived from the Terra/MODIS satellite imagery (Vermote, 2015). This product has high (for regional-scale studies) spatial resolution of $\sim 500$ $\mathrm{m} / \mathrm{pix}$, and 8-day time resolution that appears low for operative monitoring. Due to the lack of time resolution, now we elaborate approach to implementation MOD09GA Version 6, that is similar to the MOD09A1, but has 1-day time resolution. Basing on the reflectance data stored in MOD09GA channels, we compute analyse annual graphs of the NDWI accordingly to the previously designed technique (Panidi, Tsepelev, 2017). In result of the data processing we are able to detect framing calendar dates of the spring, summer and autumn growing seasons either in the point (pixel) location or as a mean value for some area.

Using of this highly discrete data source highlights the problem of big geospatial data. To process MOD09GA dataset we attract facilities of the Google Earth Engine platform (Gorelick et al., 2017).

\section{MAPPING POSSIBILITIES}

The study is ongoing and we are able to present only the initial results of Google Earth Engine implementation in mapping of NDWI and its derivatives with high spatial and time resolution. Significant issue is that Google Earth Engine processes data in some kind of "black box" mode, so in many cases additional analysis is needed to interpret how computed values were interpolated or averaged.

Despite abovementioned problems, we discovered that implementation of Google Earth Engine in our study gain extremely faster processing of initial data when detecting growing season time frames.

On the example of three meteorological stations, we detected growing season frames and lengths for the period of 2000-2018. Values for 2018 are presented in the Tab. 1.

\begin{tabular}{|c|c|c|c|c|c|c|}
\hline $\begin{array}{c}\text { Station } \\
\text { name }\end{array}$ & 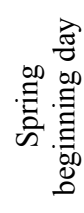 & 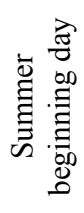 & 声急 & 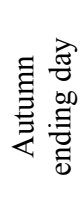 & 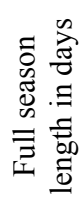 & 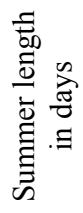 \\
\hline Petrun' & 174 & 188 & 260 & 273 & 99 & 72 \\
\hline Irael & 173 & 180 & 260 & 265 & 92 & 80 \\
\hline Ust'-Vym' & 136 & 151 & 236 & 265 & 129 & 85 \\
\hline
\end{tabular}

Table 1. Framing dates and lengths of growing seasons in 2018 detected at positions of meteorological stations using NDWI

NDWI maps were masked to exclude water bodies from computations. Growing seasons were detected basing on NDWI values averaged in $10 \mathrm{~km}$ window around every meteorological station. The window size was selected accordingly to the recommendations of World Meteorological Organization (WMO, 2012). Station positions were selected to ensure benchmarking using data of surface air temperature observations.

Annual NDWI graphs with 1-day step are presented in Fig. 2-4. As the initial graphs were noised due to the aberrations of used dataset and due to the weather (and vegetation cower) instability (Panidi et al., 2019), we applied graph smoothing using 5-day sliding window.

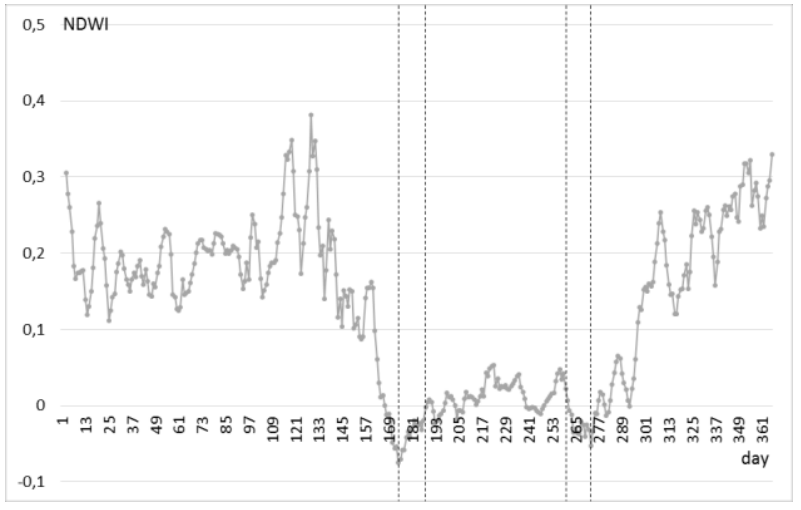

Figure 2. Annual NDWI graph of 2018 for the Petrun' meteorological station; values are averaged using 5-day sliding window; time frames of growing seasons are marked by dashed vertical lines

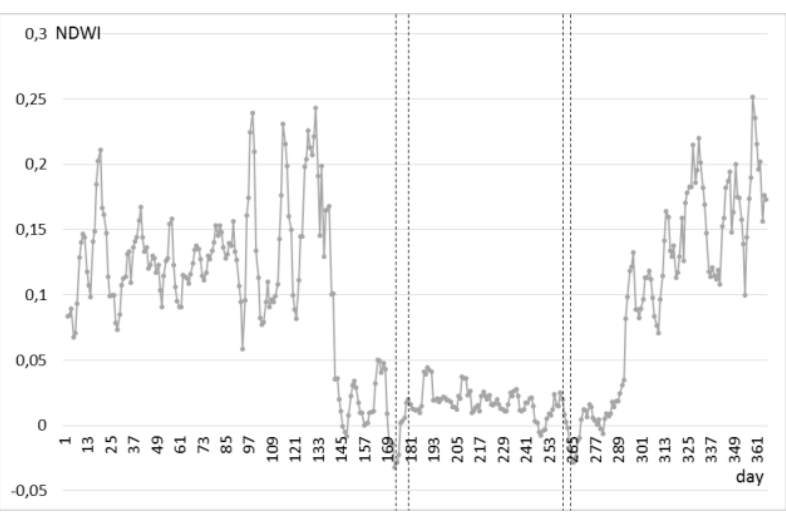

Figure 3. Annual NDWI graph of 2018 for the Irael meteorological station; values are averaged using 5-day sliding window; time frames of growing seasons are marked by dashed vertical lines

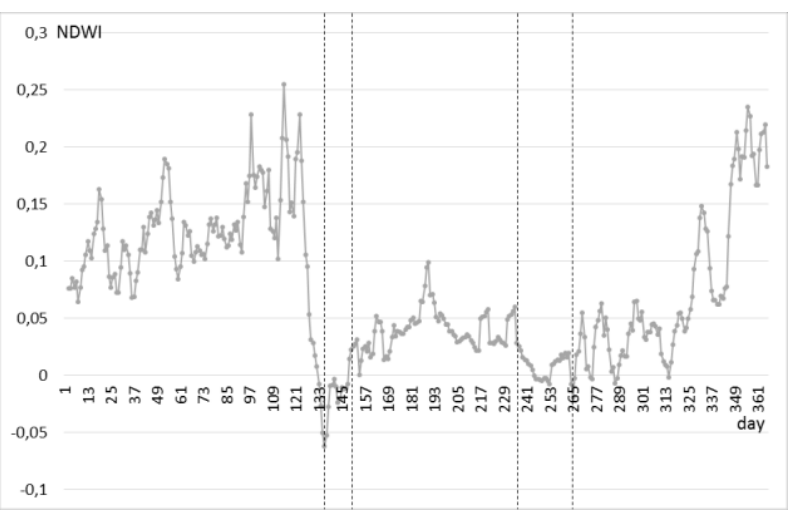

Figure 4. Annual NDWI graph of 2018 for the Ust'-Vym' meteorological station; values are averaged using 5-day sliding window; time frames of growing seasons are marked by dashed vertical lines

Using growing season parameters (detected currently at the locations of meteorological stations), we are able to provide spatial interpolation and mapping of growing season dynamics (Fig. 5-10). In this way, spatial differentiation is reflected directly on the maps, while time dynamics can be observed using map series compiled for a number of years. 


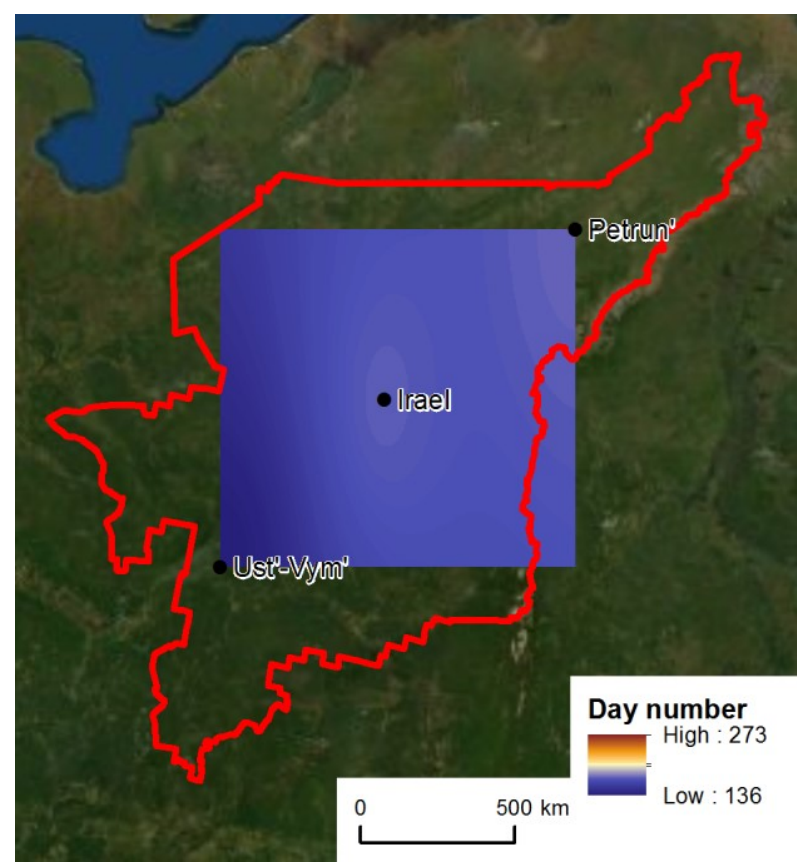

Figure 5. Beginning days of spring growing season interpolated between meteorological stations

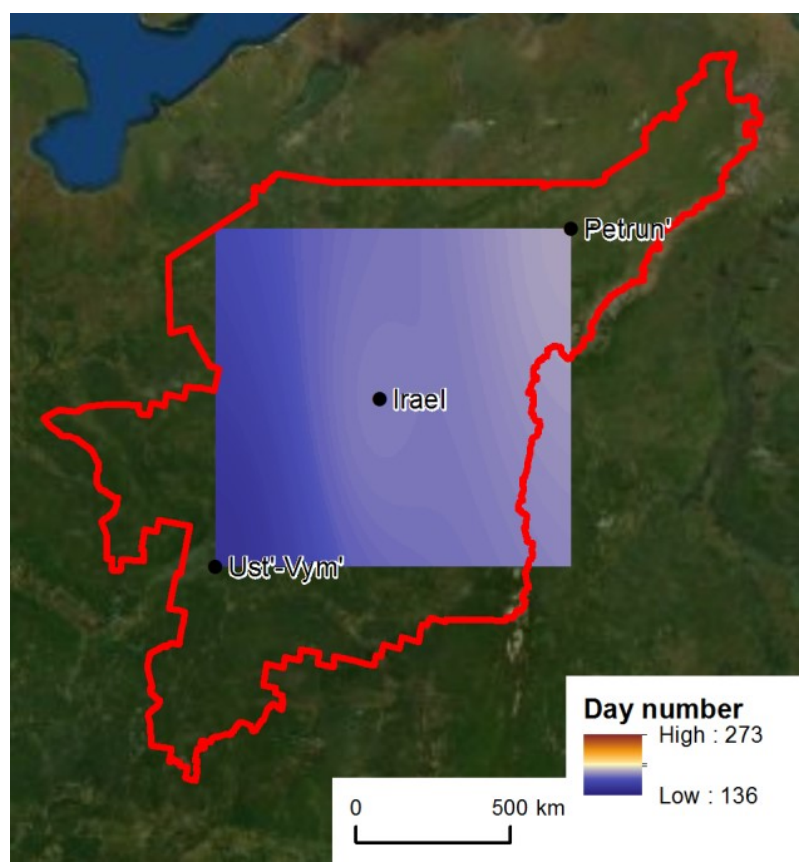

Figure 6. Beginning days of summer growing season interpolated between meteorological stations

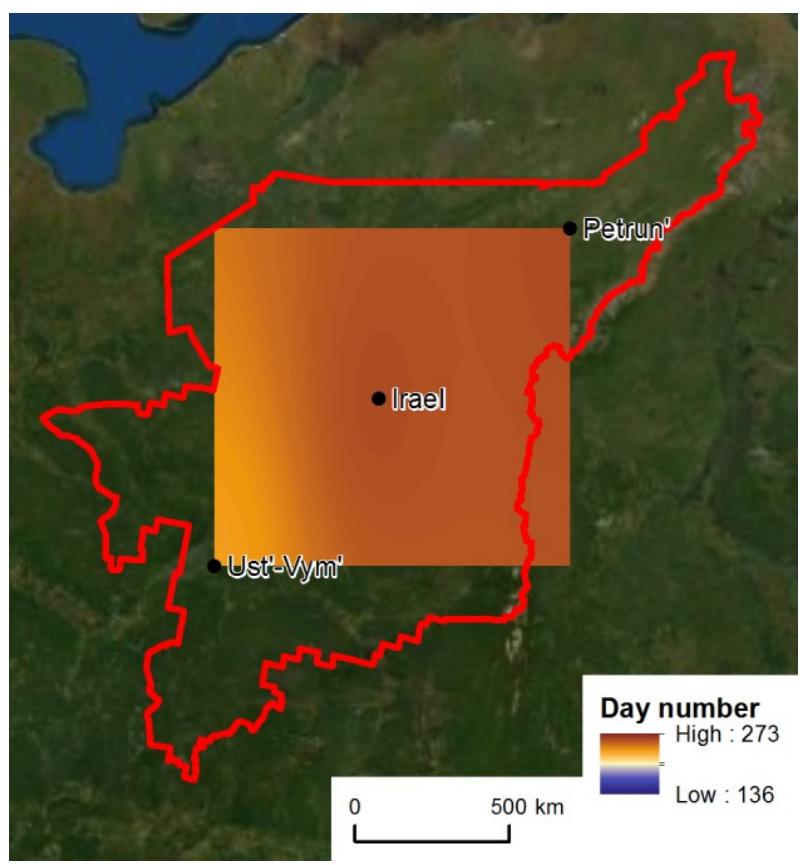

Figure 7. Beginning days of autumn growing season interpolated between meteorological stations

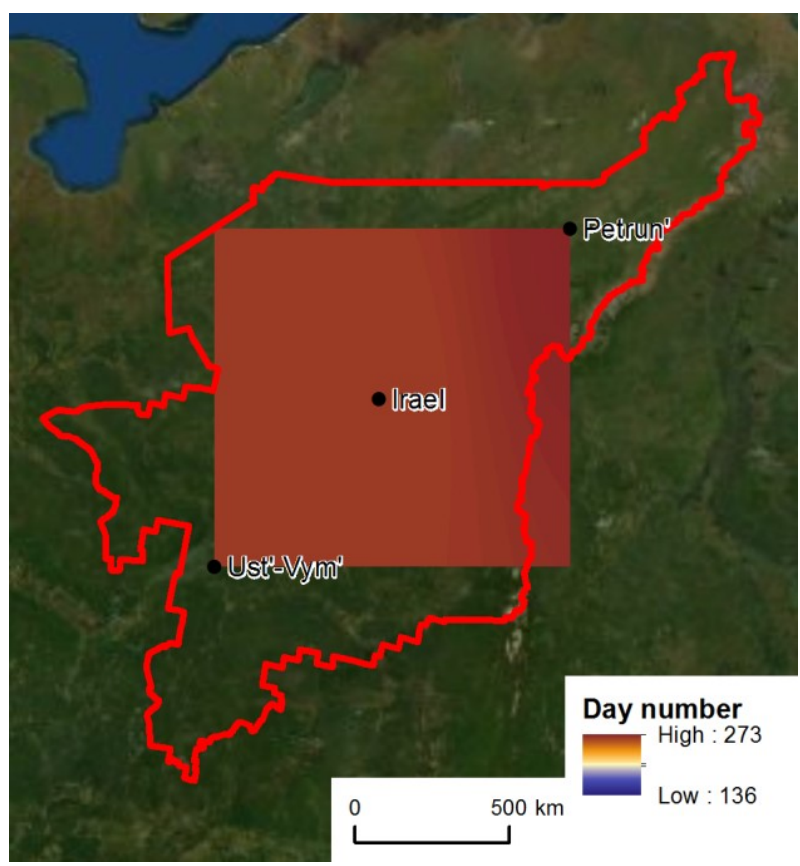

Figure 8. Ending days of spring growing season interpolated between meteorological stations 


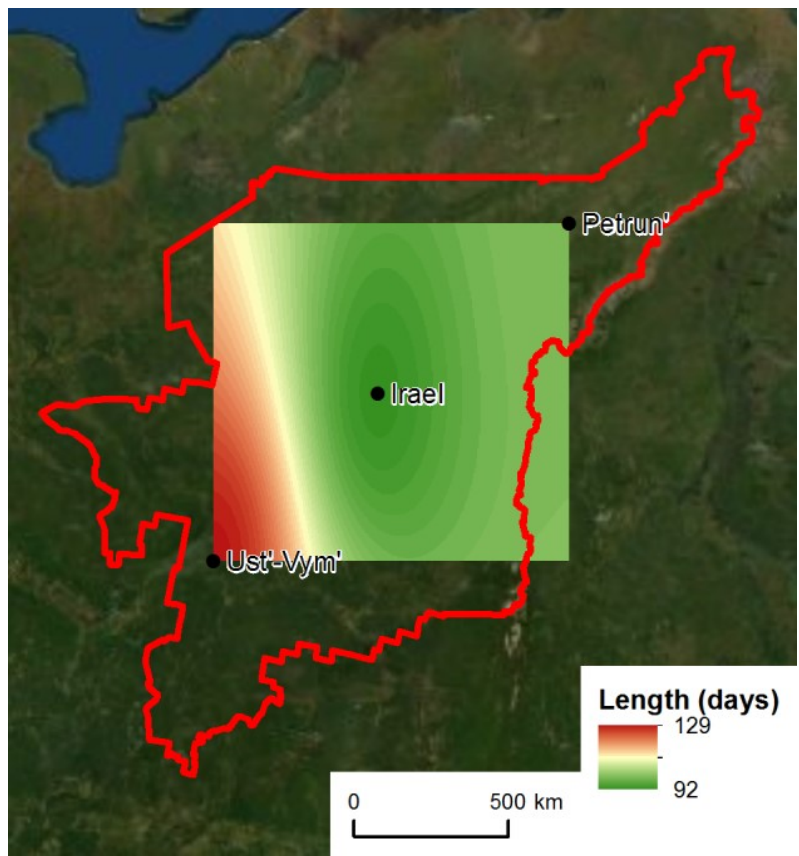

Figure 9. Lengths of full growing season interpolated between meteorological stations

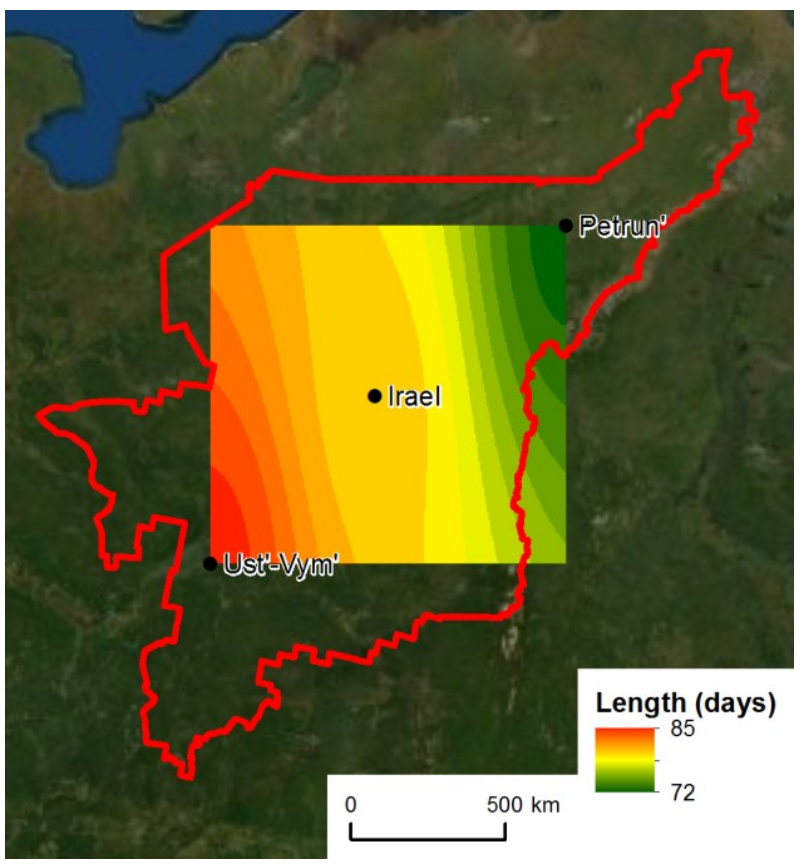

Figure 10. Lengths of summer growing season interpolated between meteorological stations

\section{CONCLUSIONS}

Taking into account huge size of MOD09GA dataset that we used to detect growing season time frames we have implemented Google Earth Engine big geospatial data platform in our study. This approach helps us to automate detection of growing seasons and ensures fast data processing.

Currently we are presenting first results of growing season mapping implemented upon the analysis of high spatial and time resolution remote sensing data. We have estimated growing season parameters at the locations of three meteorological stations through direct computations, and between the stations through the spatial interpolation. However, it is clear that growing season parameters can be directly estimated (computed) with any needed discreetness (up to the spatial resolution of initial NDWI maps, that is $\sim 500 \mathrm{~m} / \mathrm{pix}$ ). Such a high discreetness ensures monitoring of growing season dynamics on regional scale and can be demanded in climate studies and in weather/climate hazard prevention planning.

\section{ACKNOWLEDGEMENTS}

The MOD09GA Version 6 product was retrieved through the Google Earth Engine platform: courtesy of the NASA EOSDIS Land Processes Distributed Active Archive Center (LP DAAC), USGS/Earth Resources Observation and Science (EROS) Center (https://lpdaac.usgs.gov/products/mod09gav006/). doi:10.5067/MODIS/MOD09GA.006

Google Earth Engine platform: courtesy of GoogleTM (https://earthengine.google.com/platform/).

\section{REFERENCES}

Delbart, N.J-P., Kergoats, L., Le Toan, T., Lhermitte, J., Picard, G., 2005: Determination of Phenological Dates in Boreal Regions Using Normalized Difference Water Index. Remote Sens. of Env., 97(1), 26-38. doi:10.1016/j.rse.2005.03.011

Gao, B.C., 1996: NDWI A Normalized Difference Water Index for Remote Sensing of Vegetation Liquid Water From Space. Remote Sens. of Env., 58(3), 257-266.

Gorelick, N., Hancher, M., Dixon, M., Ilyushchenko, S., Thau, D, Moore, R., 2017: Google Earth Engine: planetary-scale geospatial analysis for everyone. Remote Sens. of Env., 202, 18 27. doi:10.1016/j.rse.2017.06.031

Medvedeva, M.A., Bartalev, S.A., Lupyan, E.A., Matveev, A.M., Tolpin, V.A., Poida, A.A., 2008: The Possibility of Estimation of the Growing Season Onset Basing on Satellite and Meteorological Data. Sovremennye Problemy Distantsionnogo Zondirovaniya Zemli iz Kosmosa [Contemp. Probl. of Remote Sens. of the Earth from Space], 5(2), 313-321. (in Russian)

Miklashevich, T.S., Bartalev, S.A., 2016: Method for estimating vegetation cover phenological characteristics. Sovremennye Problemy Distantsionnogo Zondirovaniya Zemli iz Kosmosa [Contemp. Probl. of Remote Sens. of the Earth from Space], 13(1), 9-24. doi:10.21046/2070-7401-2016-13-1-9-24 (in Russian)

MOD09GA Version 6 product. doi:10.5067/MODIS/MOD09GA.006

Panidi, E., Rykin, I., Nico, G., Tsepelev, V., 2019: Toward Satellite-based Estimation of Growing Season Framing Dates in Conditions of Unstable Weather. Adv. in Remote Sens. and Geo Inf. App., Adv. in Sci., Tech. \& Innov., Springer, 131-133. doi:10.1007/978-3-030-01440-7 31

Panidi, E., Tsepelev, V., 2017: NDWI-based Technique for Detection of Change Dates of the Growing Seasons in Russian Subarctic. Int. Arch. Photogramm. Remote Sens. Spatial Inf. Sci. XLII-3/W2, 179-182. doi:10.5194/isprs-archives-XLII-3W2-179-2017 
Sekhon, N.S., Hassan, Q.K., Sleep, R.W., 2010: A Remote Sensing Based System to Predict Early Spring Phenology Over Boreal Forest. Int. Arch. Photogramm. Remote Sens. Spatial Inf. Sci., XXXVIII(1), 5 p.

Tsepelev, V., Panidi, E., Torlopova, N., Bobkov, A., 2015: Study of Climate Change at the North of European Russia Using Land Cover Data. SGEM2015 Conference Proceedings, 3(2), 529-536. doi:10.5593/SGEM2015/B32/S14.071

Vermote, E., 2015: MOD09A1 MODIS/Terra Surface Reflectance 8-Day L3 Global 500m SIN Grid V006. NASA EOSDIS Land Processes DAAC. doi:10.5067/MODIS/MOD09A1.006

WMO, 2012: Guide to Meteorological Instruments and Methods of Observation WMO-No., 2008 edition updated in 2010

Revised July 2019 